\title{
Investigating Indonesian teachers' experience, motivation, and confidence in English-medium content teaching through a professional development blended learning environment
}

\author{
Mangasa Aritonang
}

\begin{abstract}
A blended learning approach has been adopted in many English language learning environments in secondary and higher education because it is seen as having the potential to maximise the benefits of both face-to-face and online learning. This research investigated a blended learning approach for the professional development of teachers working at Indonesian vocational schools who learned English so they could teach their subject in that language. This research was prompted by the lack of preparedness and confidence among Indonesian teachers in vocational high schools to use English as a medium of instruction in the classroom, even though they had attended training courses in a face-toface mode. The face-to-face training programme was a one-off brief course with limited capacity, able to accommodate only one teacher from one school. After the training programme was concluded, teachers returned to their home schools; were isolated from their peers in the training course; and consequently the learning interaction was not maintained.
\end{abstract}

To understand the teachers' learning and thinking in the blended learning programme, the conceptual framework for the research was developed based on social constructivist and adult learning theories that were applied in the blended learning course. The development of teachers' pedagogical content knowledge (PCK) in an English-medium teaching environment, the quality principles of a blended learning approach, and the concepts of motivation and confidence were considered to better understand the complexities involved in the blended learning model.

As this research sought to discover the subjective experiences and multiple perspectives perceived by the teacher participants undertaking a blended learning course, a qualitative case study approach was adopted. A case study method allowed me to work closely with the teacher participants to obtain their perspectives and was helpful to understand complex phenomena such as motivation and confidence. Sixteen teachers from three Indonesian vocational schools participated in an English languagelearning course using a blended learning approach. Data were collected through pre- and post-surveys, semi-structured interviews, teachers' reflective journals, classroom observations, and documents, and analysed using thematic data analysis and an inductive approach.

The findings of the research were categorised according to the research questions. Teacher participants reported that peer interaction and collaboration both in face-to-face and online sections of the blended learning course were the technology-mediated learning activities that contributed to the enhancement of their teaching skills in an English-medium content teaching environment. Teacher participants also reported that their motivation to learn and confidence to use English for content teaching increased.

Wilf Malcolm Institute of Educational Research, Faculty of Education, University of Waikato, Hamilton, New Zealand ISSN: 2382-0373

Permanent Research Commons link to full thesis: http://hdl.handle.net/10289/10250 (pp. 99-100) 
The teachers' self-reports were consistent with observation data. Factors that contributed to the increased motivation and confidence were reported, including the learning experiences of the teacher participants, peers feedback, and positive responses from students subsequently taught by teachers who undertook the course. Online cohort-based interaction was reported as having contributed to the gradual increase of using English for content teaching. The learning experience in the blended learning course inspired the teachers to integrate social networking sites such as Facebook and Edmodo in their teaching practice.

This discussion of blended learning practice is structured around several key themes and topics. The first looks at how mediated interaction occurred in the blended learning course, including social mediation, self-mediation, and artefact mediation. The second examines factors that made collaboration occur in the blended learning course. A third theme is that of the increased confidence of the teachers involved. The transformation of instrumental into integrative motivation through factors such as social interaction is a fourth topic of interest. The fifth is how teachers developed their PCK in an English-medium content teaching environment. How English language learning was sustained through online interaction, in relation to important issues of behavioural change and social presence, constituted the sixth topic. Lastly, the research will discuss the social constructivist perspectives involved in the blended learning course.

The research suggests a blended learning design has the potential to enhance the teaching skills, motivation, and confidence of Indonesian teachers in an English-medium content teaching environment. The design of a blended learning course should promote peer interaction and collaboration. 